\title{
The Use of Probabilistic Networks for Analysis of Smoke Spread and the Egress of People in Buildings
}

\author{
WAI-CHING TERESA LING \\ Department of Mathematics and Science \\ City Polytechnic of Hong Kong \\ ROBERT BRADY WILLIAMSON \\ Department of Civil Engineering, University of California \\ Berkeley, California 94720, USA
}

\section{ABSTRACT}

This paper focuses on the use of a network analysis approach to solve the fire safety problem associated with the spread of smoke and the probability of escape by the occupants before the fire and/or smoke blocks their path. Many random factors affecting smoke production and spread can be accounted for by coupling each smoke spread network to a given fire spread network. Smoke spread is examined for different fire scenarios, and the occupants' egress probleri is treated as a dynamic network flow problem for a given fire scenario. The time to detection and to untenable conditions, as calculated from the smoke spread network, determine the time period of the dynamic network under consideration.

\section{INTRODUCTION}

Determining the spread of fire and smoke between rooms in buildings and other structures is one of the unsolved problems of fire protection engineering. Extensive research has been carried out in the area of fire growth and smoke production within the "room-of-origin", which has contributed to a better understanding of one aspect of the fire and smoke spread problem between rooms. The other aspect of this problem is strongly probabilistic, and although deterministic modeling can be extended from the room-of-origin models, the solution to this problem will depend on a quantitative treatment of the stochastic aspects of the process.

The application of networks to solve different fire protection problems has been suggested by several writers. Elms, Buchanan and Dusing [1] represented possible paths by defining the rooms as nodes and the links between these nodes as possible paths for room to room fire spread. Berlin, Dutt and Gupta [2] also depicted a building as a network; however, their nodes represented the location of the occupants, and their links the possible exit paths for these occupants in the case of a fire. Ling and Williamson [3,4] used Elms et al.'s approach for representing the fire spread, and they associated an element of time as well as a probability with each link. This paper focuses on the use of a network analysis approach to solve the fire safety problem associated with the spread of smoke and the probability of escape by the occupants before the fire and/or smoke blocks their path. 
In recent years, most research efforts dealing with smoke problems have been concentrating on the measurement of smoke, the reduction of smoke potential of materials, and active smoke control within buildings. High rise smoke simulation experiments have been conducted to quantitatively measure the smoke movement under controlled and uncontrolled conditions $[5,6,7]$. It should be noted that all these experiments were conducted for vertical smoke movements.

In their analysis of fire spread networks, Ling and Williamson $[3,4]$ calculated the probability of occurrence for each fire scenario by means of an equivalent fire spread network using Mirchandani's algorithm [8]. The same approach is used in this paper for representing both the spread of smoke and the egress of occupants in buildings. Many random factors affecting smoke production and spread can be accounted for by coupling each smoke spread network to a given fire spread network. Smoke spread is thus examined for different fire scenarios, and in a similar fashion, the occupants egress problem is treated as a dynamic network flow problem for a given fire scenario. The time to detection and to untenable conditions, as calculated from the smoke spread network, determine the time period of the dynamic network under consideration. With additional data input into the network regarding the number of occupants in each room and the degree of mobility of the occupants, the question "are all the occupants able to escape without injury in the time allowed" can be answered.

\section{CONSTRUCTION OF A PROBABILISTTC HORIZONTAL SMOKE SPREAD NETWORK}

The framework for the construction of a smoke spread network will be laid out in this section. Nodes will represent space as well as the smoke conditions of that space. Links will represent possible movement of smoke from space to space, or the transition of different smoke conditions within that space. Smoke conditions of special interest with respect to detection and exiting of occupants will be discussed below.

If there are operative smoke detectors, they sound the alarm when smoke reaches a threshold quantity in the vicinity of the detector. In the probabilistic smoke spread network, this possible detection state will be depicted by a star-shaped node

Cooper [9] has suggested that a hazardous condition for safe egress exists when either the smoke/toxic layer has dropped down to $.91 \mathrm{~m}(3 \mathrm{ft})$ above the floor, or the average temperature of the upper layer has reached $183^{\circ} \mathrm{C}$ (corresponding to $.25 \mathrm{~W} / \mathrm{cm}^{2}$ ). An untenable condition in the corridor is defined here as the time when the smoke layer drops to $.91 \mathrm{~m}$ above the floor of such a corridor. This condition is depicted by Thus represents an untenable condition in the corridor.

The method of constructing the fire spread network can also be applied to the construction of the smoke spread network. Associated with each link in the smoke spread network is a pair of numbers $\left(p_{r}, t_{r}\right)$ where $p_{r}$ represents the probability that the rate of smoke discharge in Ehe room of origin is $r$, $r$ being a material property which can be given in terms of mass of smoke particles divided by the mass of material burned per unit time, and $t$ represents the time it takes for the smoke to travel the 1ink, given that the rate of discharge is $r$. If $r$ is multiplied by the combustion rate of the material in the room of origin, it becomes a "source term" in terms of total mass of smoke particles generated per unit time. Certain smoke detectors are activated when the air passing through them has a density of smoke particles (products of combustion) exceeding a specific limit. The time $t$ is obtained by dividing the total number of particles needed for such a volume by the smoke particle generating rate. 
Once the probability distribution for $t_{n}$ associated with each link is known, Mirchandani's algorithm can be applied to construct an equivalent network for smoke spread. The reliability and the expected values can then be computed. Since an untenable condition in the corridor signals the end of safe exiting for the occupants remaining on such a floor, the horizontal smoke spread network presented in this paper considers the time it takes for smoke/toxic gases to spread from the room of fire origin to cause an untenable condition in the corridor.

The construction of a horizontal smoke spread network is presented by way of examples. The numerical evaluation of such a network is contingent upon the availability of data which, at this time, is still mostly lacking. However, the methodology is introduced in this paper to illustrate its usefulness and to suggest a direction for future data collection.

Assumptions:

To facilitate the construction of the smoke network the following general smoke behavior is assumed:

1. Movement - During the preflashover state of a fire in the room of origin, smoke will start filling up the space from the ceiling of the room down to the soffit above the door header. If the door is open, smoke will then spread to the adjacent space assumed to be the corridor. If the door is closed, smoke will first fill the whole room of origin. When a sufficient built-up of pressure is reached in this room, the smoke will begin to escape into the corridor through the door assemblies or air duct.

2. Materials - It is assumed here that the materials in the room of origin are either cellulosic or plastic. For cellulosic materials it is assumed that throughout the preflashover period the smoke/toxic gases are only a threat to the occupants in the room of origin. After flashover, particularly during the ventilation control period, it is assumed that there is a major threat to the occupants beyond the room of origin with respect to both toxic effects and visibility. In the case of plastic materials, it is assumed that they generate large quantities of thick, black smoke which, if the door is open, may cause low visibility conditions outside the room of origin even before flashover occurs. It should be noted that many plastic materials are capable of creating very toxic gases after the fire flashes over, and they continue to pose a threat to life even after the fire has gone into the fuel control period.

3. Detection - It is assumed that detection of the cellulosic smoke by means of an automatic detector (POC) or by human olfactory senses may be possible outside the room of origin at $\alpha t_{f}, 0<\alpha<1$, where $t_{f}=$ time to flashover, if the door is open. If the door is closed, detection in this area is possible only after flashover. In the case of plastic materials, even if the door to the corridor in the room of origin is closed, it is assumed that there is sufficient leakage before flashover, making detection in the corridor possible at $1 / 2 t_{f}$. And if the door to the corridor in the room of origin is open, it is assumed that detection will be accomplished at $0.1 t_{f}$.

4. Untenable Condition - It is assumed that if the door to the corridor in the room of origin is open when flasheover occurs, the corridor will become untenable instantaneously for both plastic and cellulosic materials. If the corridor door with a fire endurance of $t$ minutes is closed in the room of origin, it is assumed that in the case of cellulosic fires, the corridor will become untenable when the fire breaches the door. For plastic fires under similar conditions, it assumed that the corridor will become untenable in $1 / 2 t_{b}$ minutes after flash-over.

5. Smoke Contribution - It is assumed that there is no smoke contribution from the materials in the corridor. 
Smoke Spread Network

The floor plan shown in Fig. 1 and the basic module shown in Fig 2 . will be used to demonstrate the construction of a smoke spread network. Since it is assumed that there is no header separating the ceiling of the whole corridor $C_{1}$ through $C_{7}$, the corridor is represented by one node $C$.

In this sample illustration of the construction of a smoke spread network, the following fire scenario will be used. The fire starts in Room 1, flashes over, spreads into the corridor segment $\mathrm{C}_{1}$ via an open door and then spreads into the corridor segment $\mathrm{C}_{2}$. The path of the chosen scenario is shown in Fig. 3 (a) by means of the fire spread network. It should be noted that this represents only one of many possible fire spread paths, as described in the previous papers by Ling and Williamson $[3,4]$. When applying this methodology, one would first analyze the potential fire scenarios and their probability using Ling and Williamson's method $[3,4]$ and then construct the smoke spread networks for each viable scenario. Using the notations from the fire spread network, and the new smoke symbols ${ }_{C}$ and $E_{C}$, a probabilistic network of smoke spread from $\mathrm{Rm} 1$ to the untenable condition in the corridor is shown in Fig. 3(b).

Note that the uncertainty of fire spread was taken care of by the choice of a specific fire scenario. In other words, smoke spread is considered with the assumption that the chosen fire scenario will occur. Thus every one of the probabilities of spread time associated with the links taken directly from the

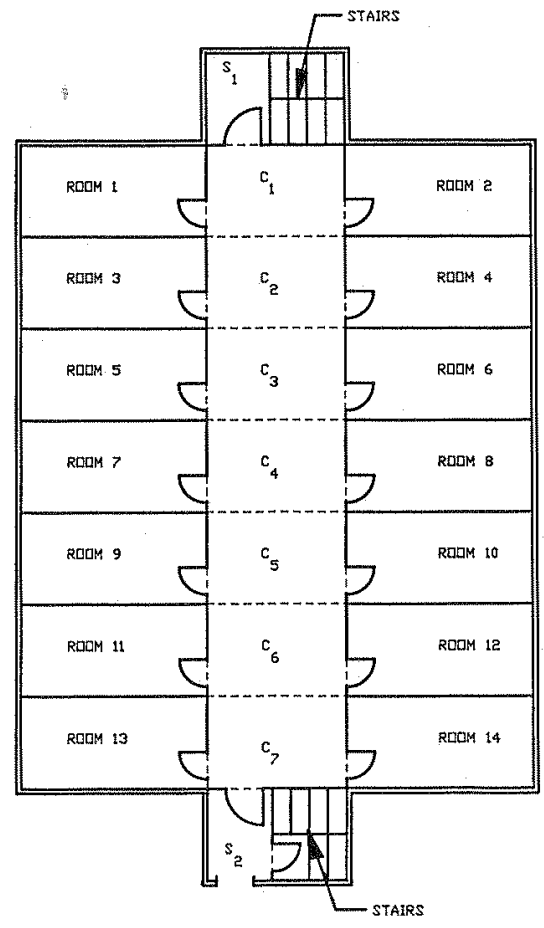

FIGURE 1. Floor plan of a typical office building, apartment or hotel.
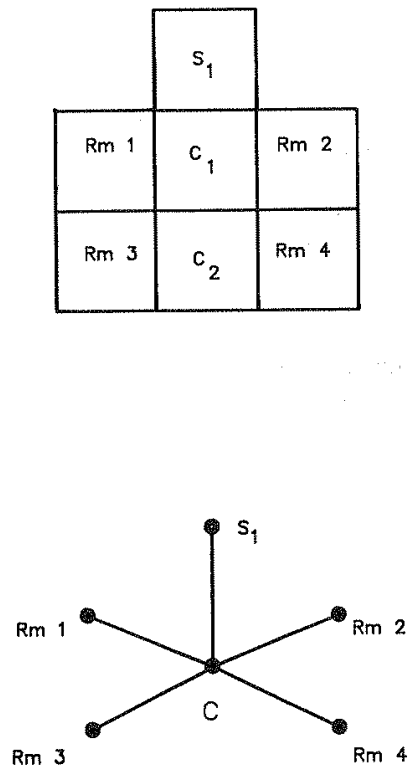

FIGURE 2, Diagram showing the transformation of a floor plan of a module (top) into a smoke spread graph (bottom). 
(a)

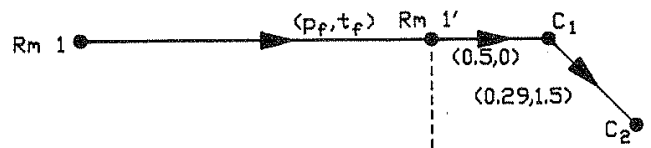

(b)

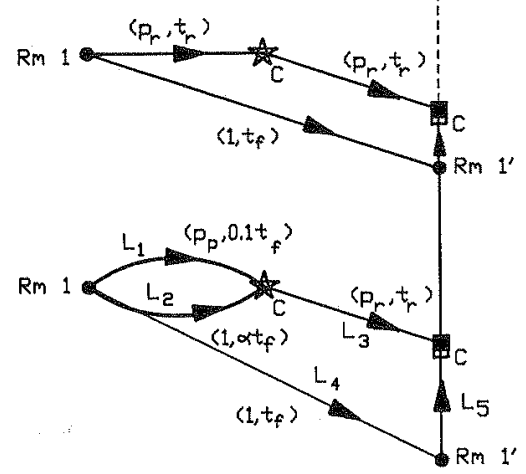

FIGURE 3. Diagram of the construction of a smoke spread network of a fire starting in Room 1, flashing over, spreading into the corridor Segment $\mathrm{C}_{1}$ via an open door and then spreading into the corridor segment $C_{2}$. (a) Fire spread network (b) Smoke spread probabilistic network (c) Smoke spread equivalent network.

fire spread network is put to unity. The equivalent network for the chosen fire scenario is constructed using the above assumptions, as shown in Fig. 3(c). The probability $p_{p}$ in $L_{1}$ represents the probability that some of the burning contents or lining materials in the room of origin are plastic. If the burning materials are not plastic, then by our assumption, they must be cellulosic causing the smoke detector to be activated at $\alpha t_{f}$ where $0<\alpha<1$. Link L in Fig. 3(c) represents the situation in which a very slow growing but smoky fire with plastic materials generates enough smoke to make the corridor untenable before the room of origin flashes over. Link $L_{4}$ is a part of the fire scenario and thus the probability is 1 , and the $t_{f}$ is dictated by the fire scenario. Link $L_{5}$ corresponds to the assumptions that the corridor door in the room of origin is open and that the corridor will become untenable instantaneously when flashover occurs for either plastic or cellulosic fires.

Figure 4 depicts the situation in which a fire flashes over in the room of origin, breaches a closed door with fire endurance $t_{b}$ and then spreads to the corridor. With these stated assumptions, the only remaining uncertainty in the smoke spread network is the probability of the room contents and linings to be of plastic materials. This scenario is thus represented in Fig. 4 where the smoke spread network is shown below the fire spread network links.

The smoke spread for the scenario in which a fire flashes over in the room of origin whose door is closed, breaches the wall and spreads to the next room, $\mathrm{Rm} 3$, is shown in Fig. 5. The fire then flashes over in Rm 3 and spreads into the corridor via an open door. In this fire scenario, even though the fire does not breach the fire door in Rm 1, the room of origin, smoke penetrates through the fire door once Rm 1 flashes over. Thus Fig. 5 shows the links $\left(p_{p}, 0.5 t_{d}\right)$ and $\left(1, t_{d}\right)$ between the detection node and the untenable node. Note that $t_{d}$ is the fire endurance of the corridor door in $\mathrm{Rm} 1$; it is larger than the endurance of the wall between $\operatorname{Rm} 1$ and $\operatorname{Rm} 3$. 


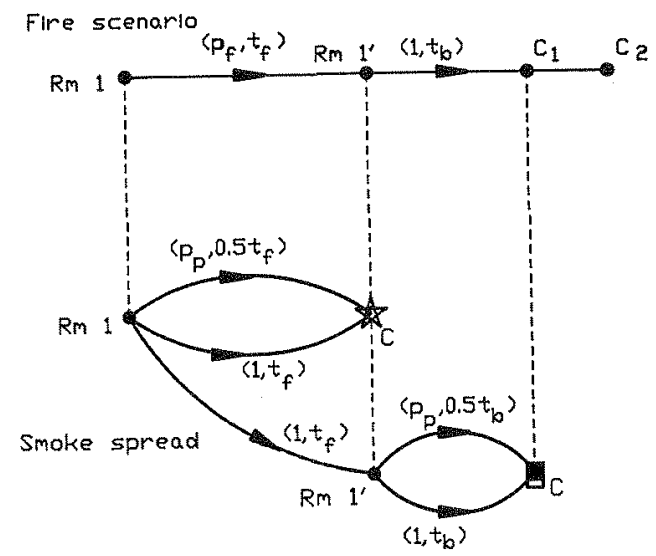

FIGURE 4. Illustration of the scenario in which the fire flashes over in the room of origin, breaches a closed door with a fire endurance $t_{\text {p }}$ and then spreads into the corridor. Here the smoke spread network is shown below the fire spread network links.

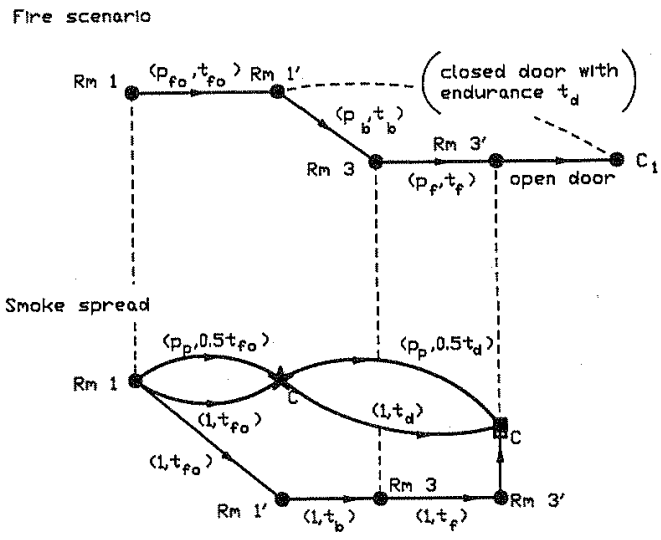

Figure 5. Diagram of the smoke spread equivalent network of the scenario in which a fire flashes over in the room of origin whose door is closed, breaches the wall and spreads into the next room, Rm 3. The fire then flashes over in Rm 3 and spreads into the corridor via an open door. This Fig. shows the links $\left(p_{p}, 0.5 t_{d}\right)$ and $\left(1, t_{d}\right)$ between the detection node and the untenable node.

After the formation of the smoke spread equivalent network, the recursive formulae shown by Ling and Williamson [4] can be applied to calculate the expected shortest spread time from ignition to the possible detection state . Similarly, the expected shortest spread time from ignition to the untenable node can be calculated. The difference between these two values represents the time available for safe egress under a given fire scenario. It is interesting to note that although fire spreads more quickly with an open door, because of possible early detection made via such an open door, the available egress time is actually longer with an open door than with a closed, unrated door. 


\section{OCCUPANT EGRESS}

Different methods for calculating the time needed for egress in case of fire are mentioned in the literature. The classic work in the field was published by Predtechenskii and Milinskii, and is now available in an English translation [10]. Their methods were used by Kendik [11] to calculate the time required to evacuate three high rise buildings. She then compared the predictions with actual evacuation tests, and estimated the "projected area factor" to be between 0.12 and $0.15 \mathrm{~m}^{2}$. Berlin, Dutt, and Gupta ${ }^{2}$ used a simulation method to evaluate the egress network for estimating the time needed for the elderly to be evacuated from rest homes. Pauls [12] reported the results of evacuation drills in Ottawa high rise office buildings. The results are given for the total time required for evacuating the whole building and the descending speed in terms of number of people per 22" width stairwells. Chalmet, Francis and Saunders [13] used the procedure of Ford and Fulkerson [14] to transform a static transshipment problem into a dynamic network flow model representing the evacuation of a building as it evolves over time, where time is represented discretely by consecutive time periods. The dynamic model, while directly minimizing the average amount of time each occupant takes to exit the building, simultaneously maximizes the total number of people to be evacuated from the building during periods 1 through $\mathrm{p}$ for all values of $\mathrm{p}$, and minimizes the time taken by the last evacuee to exit the building. This triple optimization result is mathematically proven by Jarvis and Ratliff [15].

The model for the occupants' egress is based on the framework that had been devised for the fire and smoke spread. For a given fire scenario, there is no uncertainty regarding the fire growth pattern, the detection time, or the time allowed for safe egress. Other uncertainties, such as the number and the degree of mobility of the occupants in the room at the time the fire breaks out, still remain. Once the type of occupancy for a particular building is identified, the building code sets guidelines on the maximum number of people that can be expected in each room. Although the actual number of occupants at the time of a fire is highly stochastic, the maximum number allowed by the building code can be considered as a reasonable estimate. Thus the capacity for occupancy set by the building code will be used as the number of people who need to be evacuated in a given fire situation. Given the type of occupancy, the travel time required by the occupants for exiting can now be determined from empirical data, such as those collected by Pauls [12]. In the event of mixed occupancy, the longest needed travel time should prevail. This is similar to the PERT type network in which the longest path determines the shortest project completion time. Based on the above discussed ground rules, the method for applying the dynamic network flow to the evacuation of people egress is presented in the following section.

\section{Dynamic Network Flow Model}

The first step in the construction of a dynamic network flow model is to build a static model with a floor plan in which the rooms, corridors and stairs are represented by nodes. The dynamic model is then constructed to represent the movement of occupants over time. The total time period to be considered extends from the start of the fire in the room of origin until the onset of untenable conditions blocking the last exit path. For the individual room, this time period is from the time the fire is detected until the time the path leading to safety from this room is blocked by smoke. The duration of this time period is determined from the calculation of the smoke spread network for a particular fire scenario. If the total time is divided into $K$ equal time periods, then there will be $(K+1)$ copies of the static nodes in the dynamic model. 


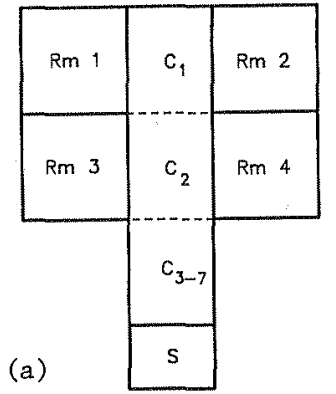

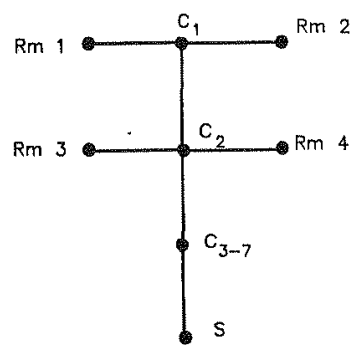

(b)

Figure 6. Illustration of the occupants egress model demonstrating use of the dynamic flow method. (a) Floor plan. (b) Graph representation

The floor plan shown in Fig. 6(a) with a graph representation shown in Fig. 6(b) will be used to demonstrate this dynamic flow method. This static model has four nodes for $\mathrm{Rm} 1$ through $\mathrm{Rm} 4$; three nodes $\mathrm{C}_{1}, \mathrm{C}_{2}$, and $\mathrm{C}_{3}$ for the corridor segments; one node $S$ for the stairs; and four nodes $\mathrm{Km}^{-7} \mathrm{H}^{4}$ through $\mathrm{Rm} 4 \mathrm{k}$ representing the state when the occupants in the room have detected the fire. Thus there is a total of twelve nodes. Note that once Rm $1 k_{n o d e}$ has been reached, the situation is irreversible and there is no need to go back to the corresponding $\mathrm{Rm} i$ node. Thus after detection of the fire, there are only eight static nodes to work with. For demonstration purposes, the following fire scenario was chosen. A cellulosic fire started in Rm 1 and spreads to the corridor via an open door. Under this fire scenario and using the assumptions described earlier, smoke will cause the whole corridor $\left(\mathrm{C}_{1}, \mathrm{C}_{2}\right.$ and $\left.\mathrm{C}_{3-7}\right)$ to become untenable as $\mathrm{Rm} 1$ flashes over. This marks the end of ${ }^{2}$ safe egress for all the occcupants still. remaining in the rooms. It is assumed that the length of time is divided into ten equal periods and the detection time for all the rooms, except the room of origin, is one time period. There are eleven copies of the static nodes. Assume the number of occupants in $\mathrm{Rm} i$ to be $a_{i}$, for $i=1$, 2,3 , and 4 . They are source inputs into the dynamic network flow. ${ }_{\text {For those }}$ nodes that do not have any occupants at the start of the fire, such as the corridor nodes, assign a capacity of zero. Construct a Iink between every copy of a node to the adjacent copy of the same node without any restrictions on the capacity for these holdover links.

The next step is to consider the links which indicate the possible movements of occupants from one area of the floor to an adjacent area. The capacity associated with each of these movement links is the maximum flow rate between nodes in terms of number of people per time period. It is assumed that the link capacity for the link leaving $\mathrm{Rm} i$ is represented by $f_{j}$ for $i=1,2,3,4$. Those between $C_{1}$ and $C_{2}, C_{2}$ and $C_{3}-7$ are represented by $f_{5}$ and $f_{6}$, respectively. Finally, the capacities for the links that go from $\mathrm{C}_{3-7}$ into the stair node $S$ are represented by $f_{7}$.

For the complete dynamic network, the holdover 1 inks and the movement links are to be combined. To simplify the network, all nonessential nodes and links are eliminated; $i . e$. the links and nodes not part of any path going from source nodes to exit nodes. In the sample network here, the source nodes are nodes $\mathrm{Rm} 1$ through $\mathrm{Rm} 4$ in time period zero, and the exit nodes are $\mathrm{S}$ nodes in al1 the time periods. The complete dynamic network is shown in Fig. 7. The dynamic network depicting the fire scenario in which a fire starts in a vacant $\mathrm{Rm} 1$ with a closed five-minute door is shown in Fig. 8. The difference between an early and a tardily detected fire can be viewed by comparing Figs. 7 and 8 . 


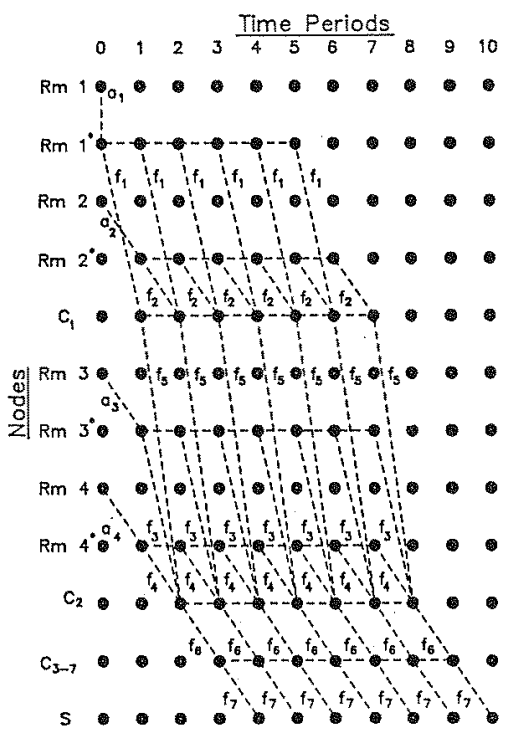

Figure 7. Diagram of a complete, dynamic network of a fire in a room whose door is open. To simplify the network, all nenessential nodes and links are eliminated.

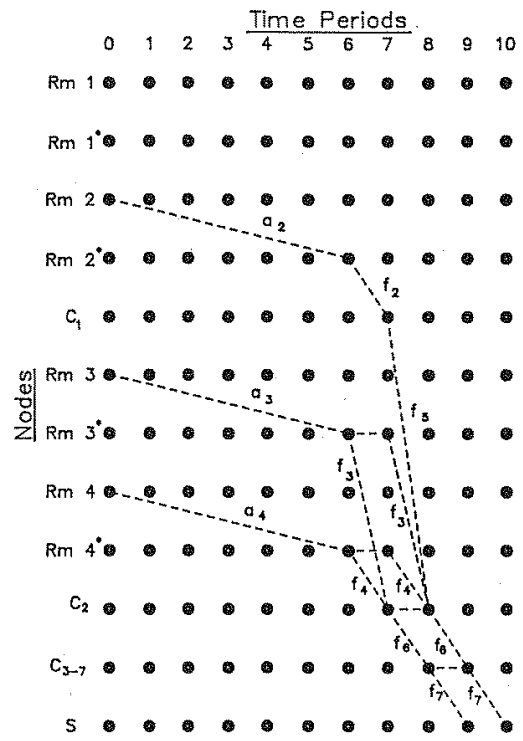

Figure 8. Complete dynamic network of a fire starting in the vacant Rm 1 which has a closed five-minute rated door. To simplify the network, all nonessential nodes and lings are eliminated.

In these examples, each link capacity is kept constant over all time periods. If data become available reflecting conditions of egress becoming more difficicult with time as the generation of smoke creates a visibility problem, even before the onset of untenable conditions, then the link capacity may be decreased for later time periods. This represents just one of the modifications that can easily be incorporated into the model whenever new relevant data become available.

Once this dynamic network is constructed, it is solved as a maximal flow problem with the flow rate limit specified by the link capacities. By the Maximum Flow-Minimal Cut Theorem, the value of the maximal flow will be at most the sum of the $a_{i}$ 's which is the total number of occupants on the floor. If the maximal flow equals the sum of the $a_{i}$ 's, the floor may be considered fire safe and all the occupants can be evactuated within the time allowed.

If the results of the dynamic flow network indicate that the egress of the occupants is not assured, a further look can be taken at the probability of occurrence for such a happening. Then the decision must be taken as to whether the risk is deemed acceptable or whether an improvement in the fire protection, such as replacing the five minute unrated corridor doors by twenty minute fire rated doors, should be undertaken. In this way, the model facilitates an evaluation and comparison of design changes. Though simplistic, the numerical examples on the four room module illustrated how the method works, and gave a good indication of the effectiveness of different fire protection measures. 


\section{ACKNOWLEDGEMENT}

The authors are greatly indebted to Professors E. Scott, R. Barlow, R. Sawyer and J. Marsden. We are also grateful to J. Hagstrom and Prof. Mirchandani for their suggestions. We thank C. Grant for her editorial assistance, and all the other colleagues who contributed to this work. The work was presented in partial fulfillment of requirements for the Ph.D. degree at UCB, and it was supported by the Nuclear Regulatory Commission through the Sandia National Laboratory in Albuquerque, NM, at the Lawrence Berkeley Laboratory, and the National Bureau of Standards, Center for Fire Research.

\section{REFERENCES}

1. Elms, D. G., Buchanan, A. H. and Dusing, J. W.: Fire Technology, 20, 1, $11-1.9,1984$

2. Berlin, G. N., Dutt, A. and Gupta, S. M.: Modeling Emergency Evacuation from Group Homes, a paper presented at the Annual Conference on Fire Research at the National Bureau of Standards, Oct. 1980.

3. Ling, W. C. T. and Williamson, R. B.: "Using Fire Tests for Quantitative Risk Analysis", in ASTM Special Publication STP 762 ed.G.T. Castino and T.Z.

Harmathy, American Society for Testing and Materials, Philadelphia, 1982.

4. Ling, W. C. T., and Williamson, R. B.: "Modeling of Fire Spread Through

Probabilistic Networks". To be published in Fire Safety Journal, 9, \#3.

5. Fung, F.C. W.: "Evaluation of a Pressurized Stairwel I Smoke Control System for a 12 Story Apartment Building," National Bureau of Standards, NBSIR 73-277, Washington, June 1973.

6. Fung, F. C. W., and Zile, R. H.: "Evaluation of Smoke Proof Stair Towers and Smoke Detector Performance," Nationa1 Bureau of Standards, NBSIR 75-701,

Washington, September 1975.

7. Tamura, G. T. and McGuire, J. H.: "The Pressurized Building Method of Controlling Smoke in High Rise Buildings," National Research Council of Canada, NRCC. 13365 , Ottawa, September 1973.

8. Mirchandani, P. B.: Computers and Operations Research, 3, 3447-355, 1976.

9. Cooper, L: "Estimating Safe Available Egress Time from Fires," National

Bureau of Standards, NBSIR 80-2172, Washington, February 1981.

10. Predtechenskii, V. M., and Milinskii,A. I.: Planning for Foot Traffic Flow in Buildings, Tr. from the Russian, Pub. for NBS and NSF by Amerind Publishing Co., New Delhi, 1978.

11. Kendik, E.:Fire Safety Journa1, 5, 3\&4, 223-232, 1983.

12.Pauls, J. L.: "Movement of People in Building Evacuations," in Human Response to Tal1 Buildings, 34, Dowden, Hutchinson \& Ross, Community Development Series, Stransburg, PA, 1977 .

13. Chalmet, L. G., Francis, R. L., and Saunders, P. B.: "Network Models for Building Evacuation," Management Science, 28, 1, 1982.

14.Ford, L. R. Jr., and Fulkerson, D. R.: Flows in Networks, Princeton University Press, Princeton, 1962.

15.Jarvis, J. J., and Ratliff, H. D.:"Some Equivalent Objectives for Dynamic Network Flow Problems, Management Science, 28, 1, 1982.

\section{NOMENCLATURE}

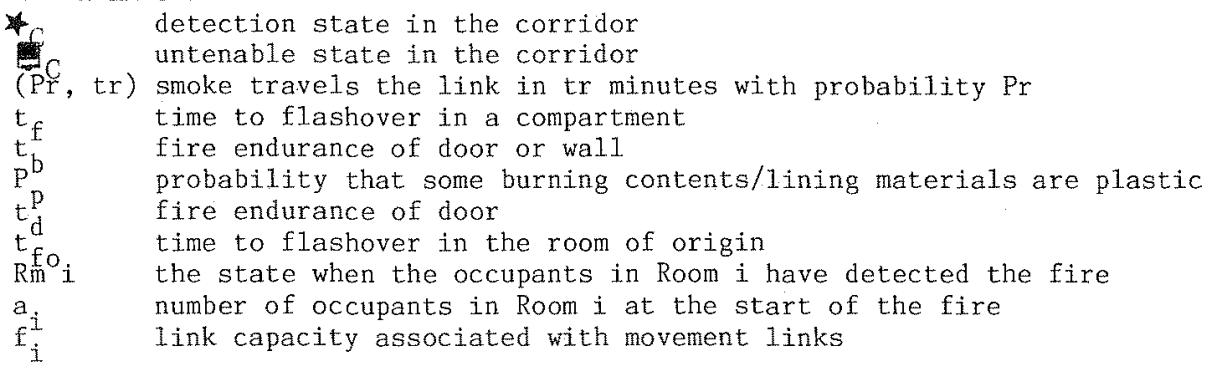

